\title{
PROTAGONISMO VIOLENTO: RASGO INTRATEXTUAL DE $L A$ CIUDAD Y LOS PERROS CON LAS OBRAS LITERARIAS DE MARIO VARGAS LLOSA (1993-2010)
}

\author{
VIOLENT PROTAGONISM: INTRATEXTUAL FEATURE OF \\ THE TIME OF THE HERO WITH THE LITERARY WORKS OF \\ MARIO VARGAS LLOSA (1993-2010)
}

Jesús Miguel Delgado Del Aguila Universidad Nacional Mayor de San Marcos (Lima, Perú)

\section{ABSTRACT}

This paper takes as a reference the novel The Time of the Hero to carry out an intratextual analysis, which is based on the unraveling of coinciding factors in the work of a single author. To achieve this goal, the following books are confronted: A Fish in the Water (1993), The Crasy of the Balconies (1993), Pretty Eyes, Ugly Pictures (1996), The notebooks of gift Rigoberto (1997), The Feast of the Goat (2000), The Way to Paradise (2003), The Bad Girl (2006), Odysseus and Penelope (2007), At the Foot of the Thames (2008), One Thousand and One Nights (2009), The Dream of the Celt (2010) and Fonchito and the Moon (2010). A peculiar feature in these texts is the treatment of aggressiveness that, for this investigation, will be called violent protagonism (a term adapted from the epistemology formulated by Mikhail Bakhtin). This concept will allow the obfuscating performance of the main characters to be recognized, ascribed to an oppressive and transgressive reality, the same that is used as justification and cause to validate this 
procedure. This will be appreciated in the areas related to family, society, politics, military organizations, ethics, sex and psychology that are reflected in the speech of the Peruvian writer Mario Vargas Llosa.

Key words: Intratextuality, violence, literary analysis, comparative analysis, literary discourse.

\section{RESUMEN}

Este artículo toma como referencia la novela La ciudad y los perros para realizar un análisis intratextual, que se basa en el desentrañamiento de factores coincidentes en la obra de un solo autor. Para lograr ese objetivo, se confrontan los siguientes libros: Elpez en el agua (1993), El loco de los balcones (1993), Ojos bonitos, cuadros feos (1996), Los cuadernos de don Rigoberto (1997), La fiesta del Chivo (2000), El Paraíso en la otra esquina (2003), Travesuras de la niña mala (2006), Odiseo y Penélope (2007), Al pie del Támesis (2008), Las mil y una noches (2009), El sueño del celta (2010) y Fonchito y la Luna (2010). Un rasgo peculiar en esos textos es el tratamiento de la agresividad que, para esta investigación, se denominará protagonismo violento (término adaptado de la epistemología formulada por Mijaíl Bajtín). Este concepto permitirá el reconocimiento del desempeño ofuscador de los personajes principales, adscritos a una realidad oprimente y transgresora, la misma que se utiliza como justificación y causa para validar ese proceder. Eso se apreciará en las áreas relacionadas con la familia, la sociedad, la política, las organizaciones militares, la ética, el sexo y la psicología que se plasman en el discurso del escritor peruano Mario Vargas Llosa.

Palabras clave: Intratextualidad, violencia, análisis literario, análisis comparativo, discurso literario.

Fecha de recepción: 22 de julio de 2020.

Fecha de aceptación: 13 de octubre de 2020.

Cómo citar: Delgado del Águila, Jesús Miguel (2020), «Protagonismo violento: rasgo intratextual de La ciudad y los perros con las obras literarias de Mario Vargas Llosa», en Actio Nova: Revista de Teoría de la Literatura y Literatura Comparada, 4: 301-323.

DOI: https://doi.org/10.15366/actionova2020.4.014 


\section{INTRODUCCIÓN}

Para empezar, el concepto de intratextualidad es una variación del que Tomás Albaladejo (2008: 8) denomina intertextualidad. Este último se caracteriza por generar una interacción comparativa entre semejanzas y diferencias, así como concatenaciones y transgresiones, para postular una cosmovisión auténtica de la realidad plasmada. En rigor, la epistemología abordada para esta investigación (la intratextualidad) cuenta con la peculiaridad de ejercer solo la asociación de referentes que pertenecen a múltiples textos del mismo autor. De esa manera, la asume José Enrique Martínez Fernández (2001: 12).

Esta pesquisa confronta con las creaciones literarias publicadas del Premio Nobel durante los años de 1993 al 2010 para que se articulen con La ciudady los perros (1963), con el propósito de comprobar la hipótesis de que los personajes adoptan un rol protagónico basado en la violencia al justificar que la sociedad en sí está corrompida por la ausencia de valores, tal como se exhibe en los ámbitos familiar, social, político, militar, ético, sexual y psicológico que se representan en las novelas o las obras de teatro. Al tratarse de una temática constante o afín en los mismos libros de Mario Vargas Llosa, se cumple ese rasgo intratextual (Martínez Fernández, 2001: 12).

Adicionalmente, he considerado la propuesta empírica de protagonismo violento al acotar la intervención del personaje principal de la obra literaria para desempeñarse en su respectivo entorno con un patrón de agresividad o impulsividad, al igual que portar una cualidad antiética. A ese talante primordial, Mijaíl Bajtín (1998: 214) le atribuye la distinción de protagonista, merced a que en este se detecta una exteriorización de conductas y comportamientos que se evalúan desde lo axiológico y que le sirven para progresar en su vida. Para Bajtín (1998: 209), no será de importancia si su actuar es bueno o malo, puesto que prevalecerá que su avance no se perjudique. Encima, su identidad se condicionará a su modo de expresarse y su círculo social (Bajtín, 1998: 156-158), sin que estos tampoco sean determinantes.

Para este análisis intratextual, elegí la novela La ciudady los perros porque esta muestra una diversidad de formas de violencia, así como personajes que evolucionaban a partir de la retención de esa modalidad castrense de supervivencia. En especial, me encaucé en la tríada 
protagónica (el Jaguar, el Poeta y el Esclavo) ${ }^{1}$ por la experimentación de la agresividad y su manifestación con intensidades variables. En su mayoría, estos personajes se tomarán como ejes para efectuar la equiparación con las obras comprendidas entre el periodo de 1993 al 2010, con el objetivo de que sus conductas concuerden con la explicación de que su proceder está garantizado por corroborar con una realidad que se halla en un estado caótico en cuanto lo moral.

\section{INTRATEXTUALIDAD DE LA CIUDAD Y LOS PERROS(1963) CON EL PEZ EN EL} AGUA (1993)

Para el caso de El pez en el agua (1993), el análisis que se realiza se refiere al género narrativo que se basa en las memorias del autor, en las que se exponen momentos esenciales de su existencia y se distribuyen como si se tratase de una crónica o un hecho histórico. Ahora, tomando en cuenta que lo intratextual (Martínez Fernández, 2001: 57-71) alude a las propiedades en común con la creación del autor, el reconocimiento de patrones está orientado a fundamentar la hipótesis de este trabajo: la justificación oportuna de los personajes en adoptar una posición que se respalda en la realidad plasmada. Así, los parentescos y las diferencias que se vinculan con la primera novela escrita por Vargas Llosa se enfocan en el ámbito sociopolítico, pero también se despliega la figura paterna, la intratextualidad directa, el contraste entre la vida política y literaria del autor, las transformaciones sufridas por el personaje principal y los distintos caracteres que irán anexos a los tópicos ya mencionados.

Al igual que en La ciudad y los perros, esta narración presenta la figura del padre violento, temerario y ausente. En ambos casos, se toma como muerto; sin embargo, no es así: solo existe un distanciamiento. Además, ante la posibilidad de considerarlo como difunto, supone una tranquilidad para el niño o el adolescente. De no ser así, se genera una sorpresa estupefacta que desemboca en agresividad, traumas y desencanto por la vida (con la distinción de que en sus memorias la reconciliación se hace propicia). El fracaso conyugal es extrínseco de forma consecuente, sobre todo, si se recuerda la unión marital entre Vargas

\footnotetext{
${ }^{1}$ En este trabajo, aludo al término tríada protagónica para incluir a los personajes el Jaguar, el Poeta y el Esclavo, quienes son frecuentes e importantes en la narración y se encuentran en un proceso de maduración en la novela, considerando en esa vía de desarrollo la articulación de la violencia.
} 
Llosa y su tía Julia, quienes son amenazados con habitualidad por el padre de él, hasta llegar a manifestar una denuncia por esa unión marital anómala.

Prevalece una asociación directa con la primera novela de Vargas Llosa, porque el autor revela los datos que le permitieron escribirla, como las vivencias en el Colegio Militar Leoncio Prado (buenas: fascinación por la lectura y el fútbol; y malas como la violencia, el racismo, las jerarquías, el alcoholismo y la pornografía), considerando que reincidir en el mal era para los cadetes un modo de ser hombres (Vargas Llosa, 2003b [1993]: 106-109) y adquirir respeto (con la negación de los principios éticos y religiosos, al fungir prácticas sexuales de fornicación y masturbación, robar, mentir, pelearse, etc.). Asimismo, ese estilo de vida se aprecia en el narrador en circunstancias relevantes, como cuando ya es un periodista bohemio de La Crónica (Vargas Llosa, 2003b [1993]: 141). Recurre con frecuencia a prostíbulos y bebe en el Negro-Negro, por la plaza San Martín. A la vez, habla y conoce de temas sobre la realidad peruana.

Vargas Llosa inicia su vida política desde que ingresó en la universidad San Marcos, junto con las lecturas que empieza a tener de autores políticos y filosóficos, que lo ayudan a denotar su pensamiento democrático e izquierdista (Sartre, Trotsky, César Vallejo, José Carlos Mariátegui, entre otros). En una ocasión, llega a conformar el Cahuide (grupo estudiantil político que se constituyó en esa institución). De forma pública, el escritor peruano llegó a pertenecer al Frente Democrático (Fredemo) (Vargas Llosa, 2003b [1993]: 44), el cual se encargaba de rechazar cualquier tipo de Gobierno dictatorial o militar, con el fin de buscar la democratización. El narrador muestra como referente el golpe realizado por el general Odría en 1948. Con esa postura, el sistema ya no enriquece a unos y empobrece más a otros. Además, es lo que el narrador percibe y designa como violencia estructural: «La discriminación, la falta de oportunidades, el desempleo y los salarios de hambre de vastos sectores de la población» (Vargas Llosa, 2003b [1993]: 213). En un inicio, ese partido se conformó por el escritor peruano en oposición a las políticas estatistas del presidente del Perú Alan García (Apra). Posteriormente, contará con apoyo de Acción Popular (dirigida, un tiempo, por Francisco Miró Quesada) y Partido Popular Cristiano (conformado por Fernando Belaúnde y Luis Bedoya Reyes). Esto conllevará que el autor participe en las elecciones presidenciales de 1990, pero no resultará vencedor, puesto que Alberto Fujimori, quien integra el grupo político Cambio 90, obtendrá la mayoría de votos. Al mismo tiempo, se vivencian las catástrofes de la violencia política (mítines, huelgas o tomas) y la lucha 
armada a través del Movimiento Revolucionario Túpac Amaru (que tuvo como una de sus funciones secuestrar a los partidarios políticos) o Patria Roja. Por eso, en ese año el aumento del terrorismo y la delincuencia persiste, junto a la protección y la vigilancia en el Perú. La labor más arriesgada era para quienes dirigieron grupos políticos, así como familiares cercanos a ellos, ya que los asesinaban, los maltrataban o los secuestraban. Pasaron muchos años de constantes guerras y conflictos, en los que la política adoptó diversas posturas y afiliaciones. Verbigracia, Vladimiro Montesinos (Vargas Llosa, 2003b [1993]: 534), quien estaba al mando del Servicio de Inteligencia de la Marina, eliminó todo rastro de delito en los registros públicos y los archivos judiciales de las operaciones ambiguas de compraventa de propiedades en las que se acusaba a Fujimori.

La política dejará de ser interés para Vargas Llosa, debido al apoyo de su esposa Patricia, quien le plantea la disyunción de su vida (literatura o política). Por ende, se muestra la práctica de la segunda como una forma de resistencia que impide desarrollar la parte creativa del escritor (y viceversa).

En El pez en el agua, se inferirá una preocupación del narrador en contar con intereses hacia el aprendizaje intelectual y literario por su compromiso social e individual. Esta forma de doctrina sapiencial la adquirirá estudiando Literatura en la universidad San Marcos, junto con el francés en la Alianza Francesa, y trabajando como investigador con su maestro Raúl Porras Barrenechea y periodista en diarios como La Crónica. En La ciudady los perros, esa instrucción es obligatoria. En consecuencia, la mayoría pretende tan solo alcanzar el conocimiento para desligarse de las adhesiones con lo opresivo y lo violento, mas no por anhelar una sabiduría cultural y fructuosa. De forma elitista, prevalecerá la cultura occidental sobre la nacional en el narrador. Esto se aprecia en dos ejemplos. El primero (Vargas Llosa, 2003b [1993]: 403) se identifica por la revelación del escritor peruano en torno a su preocupación por ganarse una beca a París, y, con esta, estudiar en Europa, para que así mejore su condición artística. De no conseguirla, se resignaría a ser un novelista con limitaciones: sin reconocimientos, mediocre, de escasa categoría, frustrado y con sus deseos truncados. El segundo (Vargas Llosa, 2003b [1993]: 417) se expone cuando afirma que más conveniente le resultaba publicar sus obras en otros países y no en Perú. Por otro lado, la literatura y la narración ayudarán, en cierta medida, a que el escritor se manifieste sociopolíticamente, al igual que la radio, la prensa y todos los medios de comunicación, ya sea para atacar una forma de gobierno o apoyar a los candidatos presidenciales. En una 
ocasión, el narrador es entrevistado por Jaime Bayly, César Hildebrandt y Ricardo Belmont. Además, esto suscita que la palabra sea un canal indispensable para inducir a disputas y malentendidos peligrosos. Se exhibe un interés del escritor en frecuentar contactos literarios, para apropiarse de conocimientos que lo ayuden a mejorar su redacción y su creatividad artística (Julio Cortázar, Sebastián Salazar Bondy, Luis Loayza, entre otros), como también la enseñanza que recibirá de sus maestros de la universidad San Marcos (uno de ellos, Carlos Eduardo Zavaleta). No obstante, más importantes serán las lecturas que él tenga con respecto a determinados autores (novelistas norteamericanos, como William Faulkner o Hemingway). $\mathrm{Al}$ proseguir esta narración, uno se percata de que la formación de Vargas Llosa, en relación con su obra, se debe al conocimiento que va adquiriendo. Esto le permite que se consideren argumentos que le servirán para sus próximas creaciones literarias y las publicaciones de las mismas, tal como sucede con Los jefes, La ciudad y los perros, La Casa Verde, La tía Julia y el escribidor, La guerra del fin del mundo, etc. Estas son puestas como testimonios en El pez en el agua. Esta parte creativa se asocia con el perfil del Poeta, quien se encarga de hacer novelitas pornográficas para sus amistades. Se observa cómo él lleva un pequeño cuaderno de apuntes y creaciones que le permite fantasear y crear mundos posibles para entretener a sus lectores de esa realidad cruel que se les presenta. Igualmente, es una forma de evasión. Los libros de Vargas Llosa traerán polémicas en los receptores de la misma, ya sea en el ámbito familiar (sobre todo, en la tía Julia y el padre de él) o el nivel nacional, tal como lo revela Elpez en el agua.

Para finiquitar, las memorias del Premio Nobel muestran transformaciones ontológicas, por las cuales atraviesa el personaje principal, ya sea en los ámbitos social y político. Un ejemplo notorio es cuando el narrador se decepciona del marxismo y el socialismo para dedicarse plenamente a otra forma de vida: la literatura en sí (Vargas Llosa, 2003b [1993]: 218), el humanismo, el matrimonio o la intelectualidad. Es más, se hallan transformaciones que implican modificaciones de intereses culturales; verbigracia, de la política a la literatura o del matrimonio al humanismo, etc. Los protagonistas de La ciudady los perros tan solo se limitan a manifestarse en una etapa precisa de sus vidas; a la vez, los espacios donde se desenvuelven no son diversos, como sí los presenta El pez en el agua. 
3. INTRATEXTUALIDAD DE LA CIUDAD Y LOS PERROS (1963) CON EL LOCO DE LOS BALCONES (1993)

El loco de los balcones (1993) se asemeja a la primera novela del escritor peruano por presentar personajes que están limitados para desarrollarse, ya sea por una carencia o una dependencia afectiva, tal como resulta con el profesor de Historia del Arte Aldo Brunelli y su hija. Para Mijaíl Bajtín (1998: 209), ese percance permite identificar las individualidades, sin importar que sea beneficioso o no para su integridad. Encima, esa determinación es propia de la hipótesis de este artículo, que consiste en adherir las conductas asumidas a la degradación que prevalece en la realidad representada.

En el primer caso, impera una frustración personal al no poder conseguir sus proyectos: la conservación de los balcones históricos de Lima, que es inadaptado para alguien contemporáneo. Asimismo, las formas que emplea para difundir su manifestación no tienen mucha trascendencia: protestas en contra de las demoliciones, pago por adquirir esos balcones, quejas ante el Dr. Asdrúval Quijano, jefe de la Dirección de Preservación del Patrimonio Artístico y Monumentos Históricos. Su obsesión por la historia y la arquitectura de su país, junto al patrimonio cultural y artístico, no son correctamente correspondidos ni solventados (Los Cruzados, conformados por doña Enriqueta, Rosa María, Ricardo y Panchín, son quienes ayudan temporalmente a este ciudadano; sin embargo, después es perjudicado por la falta de apoyo). La indiferencia de la población produce que Aldo Brunelli enloquezca e intente suicidarse. No existe ni un arrepentimiento de su parte: al ser rescatado por un borracho, luego de que probara ahorcarse, invita a ese personaje a que se una a su proyecto de resguardar los balcones, el cual acepta.

En torno a lo segundo, relacionado con la hija de Aldo Brunelli, Ileana, la limitación de cada uno se observa por la necesidad en ella de concernir con sus acciones voluntarias de colaboración a la realización personal que posee su progenitor en el proyecto de los balcones antiguos. A ello, se le añade lo que el padre quiere de ella: casarla con alguien de dinero y reputación. Le pondrá como buena alternativa a Diego Cánepa, quien cuenta con una posición económica, social y pedagógica respetable. Entretanto, muestra desagrado por un antiguo pretendiente, a quien ella quiere de verdad, apellidado Huamani, rechazado por prejuicios raciales, económicos y sociales. El truncamiento de su vida se patentiza al confesarle a su padre que él es el culpable de esa elección matrimonial fingida e interesada, 
junto al desperdicio de su vida que ha pasado con él en su proyecto de rescatar balcones, ya que este no ha tenido ni un resultado esperado.

4. INTRATEXTUALIDAd DE LA CIUDAD Y LOS PERROS (1963) CON OJOS BONITOS, CUADROS FEOS (1996)

Ojos bonitos, cuadros feos (1996) se enfoca en la historia de un intento de venganza, para lograr la transformación de un personaje (Eduardo, un severo crítico de Arte) en otro más apacible. De esto, se encarga Rubén, quien ha perdido a su novia por la ofensa que ha recibido de ese profesor sobre sus pinturas. Se exhiben varios términos que se emplean aquí y, también, en La ciudad y los perros. Esa homogeneidad determina el rasgo intratextual al que alude Enrique Martínez Fernández (2001: 19); es más, concuerda con la configuración denigrante de los personajes, que está supeditada a los eventos acaecidos en su entorno y su historia remota.

Una de las analogías es la de asimilar un rol camaleónico por parte de Rubén, quien finge ser un homosexual para introducirse a solas en el departamento del profesor. Su participación encubierta no solo se manifiesta al simular esa opción sexual, puesto que tenderá a ocultar el verdadero motivo que lo ha llevado hasta allí. Es más, hará creer que sus acciones lo conducirán al homicidio de quien la separó de su novia, pero no ocurre así: el efecto sorpresa que se alcanzará ante ello adoptará una relevancia inesperada, tan solo pretende asustar a Eduardo. El cinismo (como hacerle creer al profesor de Arte que es el mejor del vernissage), el uso del alcohol (ambos personajes beben whisky con la finalidad de lograr sus respectivos objetivos), la responsabilidad (Eduardo siente que debe decir la verdad en sus críticas y Rubén sabe que quiere conseguir un propósito en esa visita, a causa de que es el testigo más íntimo del suicidio de su novia) y la frustración (la crítica se muestra como una especie de truncamiento ante la creación artística, aunque se estancan quienes sienten que no están progresando en lo que anhelan, tal como la novia de Rubén y el profesor Eduardo) son elementos que se perciben en la primera novela de Vargas Llosa, mientras que estos otros no: la introducción de la música (se menciona que se está escuchando la canción de Gustav Mahler) y el seudoarrepentimiento (el profesor, por más que se le amenazó con una arma y casi es asesinado, no dice que modificará su actitud de ser crítico severo; sin 
embargo, recuérdese el momento en el que suplica compasión a Rubén: él le promete que iba a cambiar y le pide disculpas públicas por la crítica que le hizo a su novia, mas no llega a consumarlo después).

5. INTRATEXTUALIDAD DE LA CIUDAD Y LOS PERROS (1963) CON LOS CUADERNOS DE DON RIGOBERTO(1997)

Los cuadernos de don Rigoberto (1997) es una novela basada en contar hechos inmorales sucedidos entre don Rigoberto y doña Lucrecia, tales como la infidelidad, el lesbianismo, la separación, el abuso de la libertad, el erotismo, la perversión y el engaño. No obstante, esos temas se irán regulando con fragmentos culturales (algunos desligados totalmente de la historia central). Para finiquitar, se llegará a una síntesis de la narración en su totalidad: la reconciliación entre los esposos y la asimilación de Fonchito en sus vidas, quien ha desvirtuado a la familia por su descontrolado erotismo. A partir de ello, esa heterogeneidad de caracteres conlleva que se haga referencia a la intratextualidad (Martínez Fernández, 2001: 19), además de que esos patrones concuerdan con la configuración ontológica de los personajes, estribada en lo antiético y respaldados por un contexto afín (en ese caso, la educación defectuosa se acarreará por la familia misma, y repercutirá en la psicología y la sexualidad del afectado).

La perversidad trasciende las ficciones inventadas por Alberto Fernández en sus novelitas pornográficas que reparte a los cadetes de su sección, pues esta actúa en Los cuadernos de don Rigoberto, ya en la vida de los personajes: Fonchito desea a su madrastra, por ende, ha vencido el tabú de que los niños no deben saber sobre sexo. Asimismo, hace que ella pose eróticamente para él, como en las pinturas de su artista favorito Egon Schiele; doña Lucrecia tiene relaciones sexuales lésbicas con la nodriza Justiniana, aparte de fornicar con otros hombres y sentir atracción por su hijastro; y don Rigoberto es un padre que no corrige, evade los problemas, actúa de manera muy permisible y no confronta responsablemente la realidad. En el contexto de esta novela, se infiere que los menores son un producto consecuente de la formación y la cultura de los adultos (si ellos realizan prácticas inmorales y liberales, sus hijos también las harán). Por consiguiente, ¿quién se encarga de enrumbarlos por la vía del bien? La misma pregunta queda inconclusa en La ciudad y los perros, por la cual 
la experiencia y el arrepentimiento son los principales impulsores en generar un cambio cualitativo en los personajes, al igual que el engaño, que sirve para llevar a un bienestar individual: Fonchito unirá a Rigoberto y Lucrecia de nuevo; se basará en cartas comprometedoras hechas por él, pero hará creer a los adultos que son ellos quienes las escriben.

6. INTRATEXTUALIDAD DE LA CIUDAD Y LOS PERROS (1963) CON LA FIESTA DEL CHIVO (2000)

La fiesta del Chivo (2000) despliega cuatro temas importantes que se adhieren con la primera novela de Vargas Llosa: la revelación de la verdad (sobre Urania Cabral), la presencia de jerarquías militares, la violencia y la liberación. Ante este tipo de identificación, Jorge Lozano (Martínez Fernández, 2001: 21) manifestaba que los nexos en el discurso evocan otros contextos, como los de la historia misma. Eso ocurre en este análisis intratextual; a la vez, estos tópicos se caracterizan por la violencia medular que se corresponde con la constitución de esa realidad sociopolítica y militarizada.

Con Urania Cabral, el desentrañamiento de la verdad es destacable en la novela hasta el final de la historia. El escritor peruano empleará la técnica de las cajas chinas, así como la usa en La ciudady los perros cuando el Jaguar le está contando al flaco Higueras su desenlace amoroso con Teresa. Otro elemento hallado es el de la catarsis (los personajes se reconfortan sentimentalmente ante la declaración de una información que desconocieron de tiempo. Esto ocurrió a causa de los familiares de la historia de Urania), junto al de ir completando la historia que conforma la dictadura de Trujillo. Los estudios de Urania en Harvard, al igual que su distanciamiento con la familia y su mejor estadía socioeconómica, no suplantan el trauma que posee de pequeña: su padre (Cerebrito) fue partícipe y cómplice de la violación del Chivo. De inmediato, a ello, se le debe el tenerles miedo a los hombres y el haberse quedado soltera. Asimismo, ese odio y ese resentimiento hacia la figura paterna por su ineficacia y su irresponsabilidad en ese rol familiar se observan en la primera novela de Vargas Llosa, en la que la tríada protagónica se afecta por la mala formación conyugal de sus progenitores. 
Las jerarquías militares se someten a rangos mayores (de idéntica forma, como se efectúa en el Colegio Militar Leoncio Prado). Se toman como personajes icónicos a Fidel Castro y el «Che» Guevara, para que el dictador dominicano Rafael Leónidas Trujillo gobierne de forma autoritaria y corrupta. De allí, se destacan con rigidez el machismo y la perversión sexual de su parte, ya que República Dominicana, junto con su entorno sociopolítico, resulta perjudicada por la envidia y el deseo de venganza.

La violencia se muestra por el incumplimiento y el abuso de la ley. Verbigracia, los del Servicio de Inteligencia Militar torturan a sus presos para obtener la verdad, se castigan a los traidores del régimen, se utilizan armas, intervienen los medios de comunicación, se critica la Iglesia católica por legitimar las acciones del régimen con respecto al pueblo dominicano (Vargas Llosa, 2000: 291), se liberan a los presos políticos por parte del presidente Balaguer, se ejerce el racismo, se agrede verbalmente. Asimismo, están ausentes las manifestaciones y las protestas, porque, de ejecutarlas, el coronel Johnny Abbes contrataba a «matones» para que contrarresten cualquier tipo de sublevación (Vargas Llosa, 2000: 80). En La ciudady los perros, la violencia se emplea de forma privada, sin presencia de intermediarios; aunque este modo solo es entre tratos equitativos (de cadete a cadete).

La manera de hallar la liberación durante ese Gobierno dictatorial es con el homicidio del Chivo y los trujillistas: principales responsables de tantas traiciones y muertes. Con ello, se instala una junta cívico-militar (Vargas Llosa, 2000: 173). Por ejemplo, Pedro Livio salió de su carrera militar para sublevarse a esas autoridades. Entretanto, otros personajes se mantuvieron en ese Gobierno por temor o chantaje. Resulta complejo comparar esta forma de liberación con el Colegio Militar Leoncio Prado, puesto que las normas son distintas: un cadete matriculado en esa institución tiene la libertad de salir cuando quiera, no está condicionado, se refiere a una simulación o una virtualización, de la que se sabe cuáles son los requisitos y las tácticas para sobrevivir. Si existe liberación, se le denomina renuncia o cambio de estadio, debido a que la exclusión de un cadete no implicará la desintegración de su institución: no es de carácter político, como en La fiesta del Chivo.

7. INTRateXtualidad de LA CIUDAD Y LOS PERROS (1963) CON EL PARAÍsO EN LA OTRA ESQUINA (2003) 
El Paraiso en la otra esquina (2003) cuenta la historia de dos personajes que luchan para disuadir el abuso y las deficiencias de la sociedad. Esa peculiaridad la considera Jorge Lozano (Martínez Fernández, 2001: 21) al plantear que los nexos intratextuales son palmarios no solo con los discursos literarios, sino con los eventos históricos de la realidad, los cuales concuerdan con las manifestaciones de violencia que se exponen de manera colectiva y que son desarrolladas por autoridades incompetentes y despóticas.

Flora Tristán combatirá a favor de los derechos de la mujer (asumiendo un feminismo que está en contra de la religión) y los obreros en Francia (junto con la articulación de la Unión Obrera), para buscar el progreso y la aniquilación de las injusticias (Vargas Llosa, 2003a: 11) (por consiguiente, el exterminio del Ejército y las armas) y representarse pacifista, con el fin de lograr sus propósitos revolucionarios. Para ello, tendrá que mostrarse insensible en el amor (aunque, en una oportunidad, se enamora de la lesbiana Olympia. Sin embargo, se retira después, por el hecho de que es una limitación para sus proyectos políticos): dejará a sus hijos, se divorciará y vivirá sin vínculos con nadie. El otro personaje es Paul Gauguin (Koke), quien criticará la burguesía, y se valdrá de una tribu indígena para fungir su revolución. Esta consiste en que ese grupo de personas no pague sus impuestos. En consecuencia, le genera problemas judiciales y conseguir que sea llevado a prisión por subversivo. Los lugares en donde se abordará la acción serán en Bretaña y Tahití.

Ese interés por denunciar las anomalías que perjudican a los personajes en La ciudad y los perros no es tan evidente, pero sí prevalecen síntomas: la delación que realiza Ricardo Arana por el robo del examen de Química; el Poeta al denunciar al Jaguar y decir que en su sección los cadetes están inmersos en distintos vicios; y el Jaguar al confirmarle al teniente Gamboa que es verdad que los alumnos del Leoncio Prado hacen prácticas inmorales en su sección. A todo ello, se vincula lo apreciado en El Paraíso en la otra esquina, a causa de que en esta novela la enfermedad y los vicios preponderan para otorgar una autoayuda al personaje revolucionario: el alcohol, el sexo, la homosexualidad, la prostitución, la falta de cultura, la crítica a la religión o la violencia por las estructuras jerárquicas.

En la primera novela de Vargas Llosa, se usan los referentes de la realidad para plasmar una sensación de realismo a la lectura. En esta otra novela, también sucede lo mismo, con la diferencia de que el autor determina al inicio de cada capítulo el lugar donde se manifiestan los hechos y la fecha en la que se desenvolvieron. Por ende, se induce a una mejor ubicación espacio-temporal de lo ocurrido. 
La asociación con la literatura no es tan específica en esta novela. En cierta forma, la relación resulta más general: El Paraíso en la otra esquina revela en Paul Gauguin nociones de arte y creación. Este personaje se sirve de la pintura para exponer el salvajismo humano o la civilización. Igualmente, es muy atento al percibir elementos de la naturaleza, y anhela Francia por ser un ambiente donde se desarrolla como un artista sobresaliente. Estas pautas de la creación artística no se notan en el Poeta, ya que él solo articula las palabras en función de un tópico en particular para recibir los méritos correspondientes: la venta de novelitas pornográficas o cartas y, producto de esta, la adquisición de dinero.

\section{INTRATEXTUALIDAD DE LA CIUDAD Y LOS PERROS (1963) CON TRAVESURAS} DE LA NIÑA MALA (2006)

Travesuras de la niña mala (2006) se asemeja a la primera novela de Vargas Llosa al presentar un contexto social que afecta a los personajes; en especial, en el tipo de protagonista caracterizado por su limitación ontológica sobre los hechos. Al ser expuesto ese patrón identitario en circunstancias múltiples, acarrea la exteriorización de lo intratextual (Martínez Fernández, 2001: 19). En esta ocasión, el protagonismo violento se erige desde los requerimientos por los que atraviesan los personajes, que compromete su transmutación en los ámbitos ético, psicológico y sexual.

Si en La ciudad y los perros el Esclavo era una víctima del medio agresor, en esta oportunidad, Ricardo Somocurcio será el principal subyugado al afecto de una mujer (de forma sexual y amorosa). Los encuentros y los desencuentros en el protagonista suscitan la posibilidad de construir la narración creativa de diversas maneras. Esto provoca un acontecimiento relevante: la muerte ontológica en Ricardo (humillación e intento de suicidio), puesto que la mujer a quien desea posee una ética mal fundada que los degenera a ambos. Sin embargo, el modo de interactuar también permitirá el desentrañamiento de la verdad, como ocurre al contactarse con esa mujer, luego de unos tramos temporales de separación. Ricardo irá descubriendo algo inusitado en su personalidad. Esa actitud es muy distinta en La ciudad y los perros, en la que lo primordial se muestra casi al final de la historia. Asimismo, se compara el perfil de Ricardo Somocurcio con el del Poeta, porque ambos se adaptan a una determinada situación para sobrevivir o conseguir un propósito (Ricardo 
anhela frecuentar más a la mujer de su preferencia, y si es teniendo sexo, mejor). Además, estos dos personajes protagónicos se caracterizan por ser reflexivos, analíticos y deconstructores de los enigmas heteróclitos que se plantean en la historia (saber quién mató al Esclavo o comprender la actitud de la niña mala). La representación de la mujer en Travesuras de la niña mala es la de independiente y liberal, similar a Emma Bovary de Gustave Flaubert o María Iribarne de Ernesto Sábato (en su novela El túnel), debido a que por dentro empieza a experimentar la desintegración de su alma por la ruptura de los códigos éticos tradicionales y machistas (es infiel, alienada, prostituta, mentirosa, interesada, elitista, ruda e indiferente). El trato que lleva con el protagonista instala esa distinción inquebrantable de rangos humanos. En múltiples ocasiones, lo llama «pichiruchi» o «pobre diablo» (Vargas Llosa, 2006: 196). Y si intenta enamorarse, tan solo lo hará del hombre más violento, adinerado y desintegrado que ella ha conocido: Fukuda, un vil proxeneta que la obliga a tener prácticas sadomasoquistas con su clientela y él. Cruel personaje que se adhiere con el Jaguar, quien apertura una serie de incógnitas para comprender la forma en que la violencia es propicia para conquistar a la mujer deseada, ya que, de hacer lo contrario, tan solo se esperará el rechazo o la inacción (como le ocurre a Ricardo Somocurcio o Ricardo Arana, el Esclavo). Por lo tanto, la manifestación de la agresividad se liga con la autoconfianza.

\section{INTRATEXTUALIDAD DE LA CIUDAD Y LOS PERROS (1963) CON ODISEO Y} PENÉLOPE(2007)

Odiseo y Penélope (2007) se distingue de La ciudady los perros por presentar al personaje principal (Odiseo) que lucha en sus peripecias con la acreditación de la violencia, a causa de que se le procura matar. En cambio, en función de los cadetes del Leoncio Prado, no se requiere que se pruebe una agresión. Esta obra de teatro, estribada en La Odisea, narra los sucesos acaecidos a Odiseo, desde que partió de Troya hasta que retornó a Ítaca, donde asesinará a los nuevos pretendientes de Penélope y las sirvientas traidoras de su reinado. Lo que reluce más en este libro son los valores que surgen de esas historias verosímiles (poseen un contenido ético) y fantásticas (personajes mitológicos y seres divinos, como la participación de dioses que se manifiestan para ayudar a los humanos). Sin embargo, más notoria es la fidelidad que muestra Penélope hacia su marido durante los años de su 
separación. La ciudad y los perros devela un cuidado en la representación de un universo real posible, más realista que el de la obra de teatro, debido a que no intenta inculcar valores en el lector, sino incentivarle un espíritu crítico y exponerle las deficiencias de una sociedad regida por organismos mal fundados, en los que la violencia se adecúa. En ese sentido, lo que se aprecia como intratextual es la evolución de los personajes, siendo esa peculiaridad un componente esencial del rol protagónico (Bajtín, 1998: 24). La adaptación que asumirán con respecto a ese entorno será propicio para que sigan desarrollándose en lo ético y lo psicológico.

10. INTRATEXTUALIDAD DE LA CIUDAD Y LOS PERROS (1963) CON AL PIE DEL TÁMESIS (2008)

Al pie del Támesis (2008) es una obra de teatro que presenta un ritmo peculiar: el de ir revelando y precisando los datos sorpresivos que inquietan al personaje principal (Chispas Bellatín) y el lector. Uno de los temas a referir es el de la homosexualidad (Pirulo Saavedra se hará pasar por Raquel para entablar un diálogo con su mejor amigo de la adolescencia, luego de treinta y cinco años de separación). Otro generado por este es el recuerdo de inconvenientes (el golpe tirado por Chispas a Pirulo, porque él pretendió besarlo; o el hecho de que Raquel estaba operada como una mujer y había sido amante de Chispas sin que él antes lo supiera). En La ciudad y los perros, el libertinaje se patentiza en el alcoholismo, el asesinato, la fornicación, la violencia y el machismo: múltiples elementos que suscitan el hallazgo de lo intratextual (Martínez Fernández, 2001: 19). En ese caso, se plasma como la degradación del hombre en sí y su transformación como sujeto homosexual. De ese modo, lo externo y las experiencias desagradables provocarían que el individuo adopte una identidad poco favorable, siendo esta la tesis de este artículo. Junto a ello se van desentrañando datos, como sensaciones que tienen, frustraciones matrimoniales, relaciones pasadas, posiciones socioeconómicas, historias que desconocen, etc. Asimismo, está la obsesión por querer estar con Chispas de manera segura, por parte de Saavedra. A esta, se añade la sensación de haber perdido un tiempo valioso (la homosexualidad como una interferencia para desplegar una amistad normal y su desintegración luego de años). Para finiquitar, serán propicias la reconciliación y la declaración de la verdad (la transformación definitiva de Pirulo a Raquel). 
11. INTRATEXTUALIDAD DE LA CIUDAD Y LOS PERROS (1963) CON LAS MIL Y UNA NOCHES (2009)

Las mil y una noches (2009) es una obra de teatro que presenta un contacto directo con la original del Oriente medieval. Al contar con esa configuración, se cumple la premisa de José Enrique Martínez Fernández (2001: 69), que sostiene que todo texto se puede leer desde otro.

Esta obra relata la reconciliación que se logra entre el rey Sahrigar por su mujer Sherezada. Pero, para conseguir ese acto, ella deberá contarle historias buenas e intrigantes, que parecen no acabar. Ella le había sido infiel, al igual que las demás mujeres de su harem, cuando él salió; a su regreso, las ahorca a todas, menos a esta última (su conducta se explica en función de la hipótesis de esta pesquisa: lo externo influye para que el protagonista desempeñe un rol desmerecido). Sus narraciones abordan el interés humano de persistir en sus proyectos personales (casarse con la mujer a quien uno desea de verdad y perdurar junto a ella en lo sucesivo). A la vez, Sahrigar se va encariñando, tienen sexo y la va perdonando paulatinamente. Al final, revela que han estado mil y una noches escuchando los relatos. La ficción hizo que el rey se humanice más y ame con mayor ternura a su mujer.

Ahora, el vínculo que se establece con La ciudady los perros es el siguiente: la violencia existe en lo que sucede y lo que narra Sherezada en sus cuentos. Hay homicidios, maldad, frustraciones, separaciones, encubrimiento de la verdad, entre otros. Sin embargo, también predomina el perdón. En la primera novela de Vargas Llosa, se constatan la reconciliación y el matrimonio entre Teresa y el Jaguar; mas los modos de lograrlos son muy distintos: allí la experiencia del protagonista y el tiempo son los que hacen madurarlo y lo orientan a la práctica del bien, mientras que en Las mil y una noches la enseñanza de valores es la que va formando el espíritu óptimo de Sahrigar, mediante los relatos de su mujer Sherezada.

12. INTRATEXTUALIDAD DE LA CIUDAD Y LOS PERROS (1963) CON EL SUEÑO DEL CELTA (2010)

El sueño del celta (2010) se relaciona con numerosos caracteres de la novela que está siendo analizada. Esa heterogeneidad es un talante fundamental de lo intratextual (Martínez 
Fernández, 2001: 19), ya que facilita el nexo entre las obras. Para este caso, permitirá discernir el incentivo de los protagonistas por actuar de una determinada manera, asumiendo que la sociedad está mal estructurada. El principal impulsor que se observa es el de la violencia, pues aquí será más preeminente: torturas; maltrato y asesinato a las tribus indígenas del África y América, como los ocurridos a los huitotos o los boras; esclavización, sobre todo, para el tráfico del caucho; condenas a muerte, como la sufrida por el protagonista Roger Casement; violaciones; homosexualidad; jerarquías; chantajes; etc. No obstante, esta se justifica, al igual que en La ciudady los perros, por los avances progresistas y civilizadores — la violencia, además, se desarrolla en sus tres niveles: verbal, actancial y espacial-. A diferencia de la tríada protagónica, no se distingue un cambio rotundo en Roger Casement: se mantiene en la concepción de luchar por sus ideologías hasta fallecer, no se arrepentirá por lo ocasionado; es más, reconoce que su muerte será un aviso de emergencia a la sociedad. De esta forma, no llegará a ser reconocido. Ante lo que piense o sienta, también se implican los riesgos que tendrá entre Alemania, Inglaterra e Irlanda. En algunas oportunidades, deberá emular a otro sujeto y preparar una sublevación, que lo conduce a ser acusado como conspirador. Prevalece un distanciamiento del personaje con la formación familiar, al igual que en la primera novela de Vargas Llosa. En función de lo sociopolítico, se aprecia la coexistencia de una lucha frecuente por disuadir las estructuras establecidas entre los países colonizadores con los colonizados. Por otro lado, tomando en consideración la parte literaria —el Poeta se vinculaba más con la literatura al ser un creador-, el protagonista de El sueño del celta se enriquece de lo artístico para buscar una esperanza. Verbigracia, posee en su celda el libro Imitación de Cristo (asimismo, la religión modifica para bien la actitud de este personaje: se percibe cómo adopta una esperanza y un confortamiento ante su condena de muerte). Además, se dedica a ser delator mediante la escritura: informa al Foreign Office sobre los abusos de los colonizadores del Peruvian Amazon Company a los indígenas (la delación adquiere valor importante de comparación, porque la tríada protagónica tiene un interés por mostrar la verdad de los hechos, frente a un grupo de personas que vive con la aceptación de esa injusticia); incluso, publica un texto que se titula Blue Book.

13. INTRATEXTUALIDAD DE LA CIUDAD Y LOS PERROS (1963) CON FONCHITO Y LA LUNA (2010) 
Fonchito y la Luna (2010) es un cuento infantil que se distingue por el contacto con la naturaleza (su estética, su fondo y su sensibilidad) y que relata la historia del personaje Fonchito (quien es conocido ya en Elogio de la madrastra y Los cuadernos de don Rigoberto), frente a su pulsión de querer propinarle un beso en la mejilla a la chica más bonita que ha visto en su escuela, Nereida. Por referirse a un tipo de narración dedicado a un público en particular, los temas se limitan. Por ejemplo, no se aborda el tópico de la violencia o la agresión; es más, resulta todo lo contrario: muestra lo fantasioso y lo pulcro se argumentan efectivamente (la manera en que Fonchito busca bajar la Luna para ganarse el preciado beso de Nereida). Eso sí, la desidia de la niña, junto con su engaño, traslucirán un sentimiento de frustración y melancolía en el interesado. A pesar de ello, él no se rendirá, y aminorará esa limitación. No se asocia con la tríada protagónica de La ciudad y los perros, a causa de que esta emplea la violencia para lograr sus objetivos; sin embargo, poseer rasgos afines: del Jaguar, el triunfo y la conquista de la mujer que quería; del Poeta, su imaginación y su creatividad; y del Esclavo, su lado sensible y su represión motivadora.

Asimismo, la figura paterna se hace extrínseca. Don Rigoberto aparece como un instrumento de instrucción inconsciente y casual: Fonchito aprende que la proyección de la Luna se refleja en un balde con agua. Esa enseñanza fue gracias a la intervención de su padre. Aunque él lo haya colocado sin intencionalidad, su progenitor lo ayudó. En la primera novela de Vargas Llosa, la figura paterna es agresiva. En vez de construir la entidad ética de los personajes, les produce problemas y traumas que permanecerán en el tiempo. De todos modos, se genera un cambio. Debe tenerse en cuenta que las transmutaciones y la adquisición de conocimientos son propias de los protagonistas, según Mijaíl Bajtín (1998: 156-158). El entorno familiar influirá en la eficacia de esa retroalimentación de experiencias inusitadas. Así, la hipótesis de este artículo prevalece al percatarse la dualidad entre el individuo y el contexto.

\section{CONCLUSIÓN}

La conceptualización que hizo José Enrique Martínez Fernández en La intertextualidad literaria (2001) fue factible para identificar el protagonismo violento que se 
expresa en el universo textual de Mario Vargas Llosa, considerando como eje La ciudad y los perros, siendo esa conducta una justificación a la degradación de la realidad (ámbitos familiar, social, político, militar, ético, sexual y psicológico). En Elpez, en el agua (1993), se apreció esa correspondencia en cuanto la educación y las vicisitudes por las que atravesaron los personajes; incluso, se mencionan con frecuencia los malos hábitos y las remembranzas agobiantes que les acarrea malestar y denigración. En El loco de los balcones (1993), coincidió en esa configuración atípica que se ha efectuado en el protagonista, quien desea conservar su vivienda como símbolo de apropiación del pasado inexistente; a la vez, plasma el rechazo al porvenir y la realidad. En Ojos bonitos, cuadros feos (1996), se mostró el tópico de protagonismo violento debido a que se consolida una atmósfera supeditada a la maldad, la venganza y el odio que proviene de Rubén y que ha sido originada por el comentario severo del crítico Eduardo por una pintura. Asimismo, es necesario reanudar la combinación de actitudes que facilitará una óptima apariencia para que concrete su objetivo: un homicidio. En Los cuadernos de don Rigoberto (1997), reincide el tema de lo perverso en el ámbito sexual. Se tomó en cuenta que en La ciudady los perros esos actos se patentizaban para menospreciar al resto de cadetes o instaurar un prototipo de respeto y miedo hacia los demás. En el caso de esta novela, su exhibición provoca una concatenación irreparable de sucesos malévolos en la que el personaje Fonchito se erige desde la sinrazón y el oprobio de la moralidad. En La fiesta del Chivo (2000), se evocó la deficiente formación familiar para justificar la pesadumbre de Urania Cabral, quien no ha podido superar el trauma de su abuso sexual. En El Paraíso en la otra esquina (2003), fue notorio ese acto de protesta de Flora Tristán contra las imposiciones tradicionales. Además, ese rasgo concuerda con el Poeta, quien intenta manifestar su versión sobre la declaración del verdadero asesino de Ricardo Arana. En Travesuras de la niña mala (2006), se mostró la ignominia del protagonista Ricardo Somocurcio al expresar su falta de autoestima, supeditada al sexo que le brindaba la niña mala de manera fortuita. En Odiseo y Penélope (2007), lo intratextual se expone en la violencia empleada con el propósito de lograr objetivos concretos, así como cuando el Jaguar agredió a los cadetes que pretendieron bautizarlo y sus compañeros, para hacerse respetar. En Alpie del Támesis (2008), la violencia no se observó de modo directo; más bien, lo que cautivó al lector fue el desenlace inesperado: el secreto de que Raquel fue anteriormente Pirulo. En Las mil y una noches (2009), se retomó el tópico del engaño que se utilizó en La ciudady los perros. A partir de este, se va erigiendo una historia que el lector alcanza diferenciar por encima de la auténtica. Sin embargo, la 
astucia del narrador permite que se corroboren relatos paralelos y alternos con el fin de encubrir el acto humillante. En El sueño del celta (2010), es fundamental detectar la repercusión caótica de Roger Casement por afiliarse a un pensamiento progresista. Eso desentraña las estructuras militares y las consecuencias perturbadoras de la intromisión de la violencia para las respectivas organizaciones, como también se evidencia en el Colegio Militar Leoncio Prado. En Fonchito y la Luna (2010), la violencia no es extrínseca, pero se toma atención a la astucia y hasta la perfidia de Nereida para impedir, obstaculizar y retar al protagonista en proponerle algo que es realmente imposible («bajarle la Luna»). 


\section{BIBLIOGRAFÍA}

Albaladejo, Tomás (2008): «Poética, literatura comparada y análisis interdiscursivo», en Acta Poética, 29 (2): 247-275.

Bajtín, Mijaíl (1998): Estética de la creación verbal, México, Siglo Veintiuno Editores.

Delgado Del Aguila, Jesús Miguel (2017): Protagonismo violento y modos de representación en La ciudad y los perros (1963), Tesis de Licenciatura, Universidad Nacional Mayor de San Marcos de Lima, Perú.

Delgado Del Aguila, Jesús Miguel (2020a): «Protagonismo violento: elemento intratextual de La ciudad y los perros con las obras literarias iniciales (1952-1977) de Vargas Llosa», en Sincronía, XXIV (78): 303-323.

Delgado Del Aguila, Jesús Miguel (2020b): «Intratextualidad en La ciudad y los perros con el tópico de protagonismo violento en sus obras literarias (1981-1993)», en Revista Espergesia, 7 (1).

Martínez Fernández, José Enrique (2001): La intertextualidad literaria, Madrid, Cátedra.

Vargas Llosa, Mario (1996): Ojos bonitos, cuadros feos, Lima, Peisa.

Vargas Llosa, Mario (1997): Los cuadernos de don Rigoberto, Madrid, Alfaguara, Peisa.

Vargas Llosa, Mario (2000): La fiesta del Chivo, Lima, Alfaguara (Bolsillo).

Vargas Llosa, Mario (2003a): El Paraíso en la otra esquina, Lima, Alfaguara.

Vargas Llosa, Mario (2003b [1993]): El pez en el agua, Bogotá, Seix Barral (Biblioteca Breve).

Vargas Llosa, Mario (2005 [1993]): El loco de los balcones, Lima, Alfaguara.

Vargas Llosa, Mario (2006): Travesuras de la niña mala, Lima, Alfaguara.

Vargas Llosa, Mario (2007): Odiseo y Penélope, Barcelona, Galaxia Gutemberg.

Vargas Llosa, Mario (2008): Al pie del Támesis, Lima, Alfaguara.

Vargas Llosa, Mario (2010a): El sueño del celta, Lima, Alfaguara.

Vargas Llosa, Mario (2010b): Fonchito y la Luna, Lima, Alfaguara.

Vargas Llosa, Mario (2010c [2009]): Las mily una noches, Lima, Alfaguara.

Vargas Llosa, Mario (2012 [1963]): La ciudad y los perros. Edición conmemorativa del cincuentenario, Italia, Alfaguara, Real Academia Española. 


\section{SOBRE EL AUTOR}

\section{Jesús Miguel Delgado Del Aguila}

Licenciado en Literatura por la Universidad Nacional Mayor de San Marcos (Lima, Perú). Egresado de la Maestría en Literatura con mención en Estudios Culturales y candidato a doctor en Literatura Peruana y Latinoamericana de la misma institución, además de ser investigador Concytec, con intereses en la narrativa y los ensayos de autores latinoamericanos, como Mario Vargas Llosa, Gabriel García Márquez y Octavio Paz. Se ha desempeñado como docente de Educación Superior y universidades nacionales; asimismo, ha trabajado como corrector de textos en editoriales. Ha publicado en revistas indexadas en Web of Science, SciELO y Scopus de Perú, Chile, Venezuela, Brasil, Costa Rica, México, Colombia, España e Italia. Ha sido ponente en congresos de Perú, Cuba, España, México, Colombia, Guatemala y Estados Unidos.

https://orcid.org/0000-0002-2633-8101

Contact information: Correo electrónico: tarmangani2088@outlook.com 